\title{
Evolution characteristics and drivers of the water level at an identical discharge in the Jingjiang reaches of the Yangtze River
}

\author{
CHAI Yuanfang ${ }^{1,2}$, 'YANG Yunping ${ }^{3,4}$, DENG Jinyun², SUN Zhaohua², LI Yitian², \\ ZHU Lingling ${ }^{2}$
}

1. Department of Earth Sciences, Vrije Universiteit Amsterdam, Boelelaan 1085, 1081 HV Amsterdam, The Netherlands;

2. State Key Laboratory of Water Resources and Hydropower Engineering Science, School of Water Resources and Hydropower Engineering, Wuhan University, Wuhan 430072, China;

3. State Key Laboratory of Hydrology-Water Resources and Hydraulic Engineering, Hohai University, Nanjing 210098, China;

4. Key Laboratory of Engineering Sediment, Tianjin Research Institutes for Water Transport Engineering, Ministry of Transport, Tianjin 300456, China;

5. Bureau of Hydrology Changjiang Water Resources Commission, Wuhan, 430010, China

\begin{abstract}
The operation of large-scale reservoirs have modified water and sediment transport processes, resulting in adjustments to the river topography and water levels. The polynomial fitting method was applied to analyze the variation characteristics of water levels under different water discharge values in the Jingjiang reach of the Yangtze River from 1991-2016. The segregation variable method was used to estimate the contributions of the varied riverbed evaluation, the downstream-controlled water level, and the comprehensive roughness on the altered water level at an identical flow. We find that low water levels in the Jingjiang reach of the Yangtze River from 1991-2016 are characterized by a significant downward trend, which has intensified since 2009. Riverbed scouring has been the dominate factor causing the reduced low water level while increased roughness alleviated this reduction. From 1991-2016, there was first a decrease followed by an increase in the high water level. The variation characteristic in terms of the "high flood discharge at a high water level" before 2003 transformed into a "middle flood discharge at a high water level" since 2009. The increased comprehensive roughness was the main reason for the increased high water level, where river scouring alleviated this rise. For navigation conditions and flood control, intensified riverbed scouring of the sandy reaches downstream from dams enhanced the effects that the downstream water level has on the upstream water level. This has led to an insufficient water depth in the reaches below the dams, which should receive immediate attention. The altered
\end{abstract}

Received: 2020-03-18 Accepted: 2020-05-21

Foundation: National Key Research and Development Program of China, No.2018YFB1600400; Open Foundation of State Key Laboratory of Hydrology-Water Resources and Hydraulic Engineering, No.2017491211; Fundamental Research Funds for Central Welfare Research Institutes, No.TKS20200312

Author: Chai Yuanfang, $\mathrm{PhD}$ Candidate, specialized in the research on the relationship between climate change and river hydrological response. E-mail: yuanfangchai@163.com

"Corresponding author: Yang Yunping, PhD and Research Assistant, E-mail: yangsan520_521@163.com 
variation characteristics of the high water level have also increased the flood pressure in the middle reaches of the Yangtze River.

Keywords: water level at identical flow; spatio-temporal evolution; channel geomorphology; middle reaches of the Yangtze River

\section{Introduction}

Water level changes directly affect a river system's stability, waterway depth, industrial and agricultural water consumption, and the ecological environment (Burns and Walker, 2015). The operation of large-scale reservoirs leads to riverbed scouring, which affects a river's water level downstream of dams. Low water levels can obstruct navigation (Yang et al., 2019) while high water levels increase the risk of flood disasters (Gabriel, 2004). As an essential engineering measure for water resource use, the effects that reservoirs have on water and sediment transport, river channel geomorphology, and river water levels have received considerable attention. For example, after reservoir operation, the river channel was undercut by up to 4-6 m downstream of dams on the Tagliamento, Piave, and Brenta Rivers in Italy (Surian et al., 2010). The Aswan Dam on the Nile River (Shields et al., 2010), Glen Canyon Dam on the Colorado River (Topping et al., 2013), Danjiangkou Dam on the Hanjiang River (Lu et al., 1994), and Three Gorges Dam on the Yangtze River (Lai et al., 2014; Yang et al., 2017a, 2017b, 2018; Han et al., 2017) have all caused lower water levels as compared with the levels pre-reservoir operation at a given water discharge. Different rivers show different variation characteristics regarding flood water levels. A study of 25 rivers in Germany found that for one river, each hydrological station had a unique trend in terms of their water levels during flooding (Bormann et al., 2011). In Kansas City, U.S.A., despite a flood water discharge in 2011 that was smaller than the discharge in 1970, the flood water level unexpectedly increased by $1.1 \mathrm{~m}$ (Caele et al., 2015). After operation of the Three Gorges Dam, there was an overall decrease in the maximum water level along the middle reaches of the Yangtze River, but the flood water level at an identical discharge rate did not display this decreasing trend (Yang et al., 2017a, 2017b, 2018; Han et al., 2017). Certain studies have even suggested that there was an increase in the flood water level (Zhang et al., 2016). For example, at the Hankou hydrological station, the water level at a discharge of $50,000 \mathrm{~m}^{3} / \mathrm{s}$ increased by up to $1.5 \mathrm{~m}$ between 2003 and 2013 (Mei et al., 2016), followed by a continual increase in the water level up to $2.2 \mathrm{~m}$, higher than that in 2013 (Yang et al., $2017,2018)$. Compared with the discharge measured in 1954, the maximum water discharge at the Luoshan hydrological station was $11,000 \mathrm{~m}^{3} / \mathrm{s}$ lower in 1998 , with an increase in the corresponding water level of $1.78 \mathrm{~m}$ (Huang et al., 2016). Similarly, the maximum water discharge in 2016 was $52,100 \mathrm{~m}^{3} / \mathrm{s}$, which was $15,700 \mathrm{~m}^{3} / \mathrm{s}$ lower than that in 1998 . However, the corresponding water level had only decreased by $0.09 \mathrm{~m}$.

Previous studies have suggested that changes to riverbeds, including riverbed erosion, have impact on low and flood water levels below dams. Changes in the water level are mainly associated with reservoir operation, riverbed erosion, riverbed roughness, and human activity (Lu 1994; Yang et al., 2017a, 2017b, 2018; Han et al., 2017). In general, riverbed scouring reduces water levels while increased riverbed roughness increases water levels (Moshe et al., 2008; Greene et al., 2014). The main influencing factors that increase riverbed roughness are vegetation growth, riverbed armoring, human activity (Yang et al., 2017a, 
2017b, 2018; Han et al., 2017; Guo et al., 2017), and upstream and downstream water levels (Guo et al., 2017; Han et al., 2011). Different parts of a channel have different influencing factors (Han et al., 2011; Sun et al., 2015). For example, vegetation growth mainly affected the 2011 flood disasters in Kansas City, U.S.A. (Carle et al., 2015). In terms of human activity, although a single water conservancy project may have little effect on the water level, the cumulative effects of numerous projects can be significant (Zhang et al., 2011). The Jingjiang reach is a key area for waterway regulation and flood control in the middle reaches of the Yangtze River, where changes in the water level have received significant attention. Although recent studies have mainly analyzed the relationships among water level, riverbed erosion, riverbed roughness, and typical human activity (Yang et al., 2017a, 2017b, 2018; Han et al., 2017; Chai et al., 2019), few studies have focused on estimating the contributions of these effects to changes in the water levels at a specific water discharge.

In this study, we collected water discharge and water level data along the Jingjiang portion in the middle reaches of the Yangtze River from 1991 to 2016. Using the polynomial fitting method, we modeled the regression relationship between the water level and water discharge to analyze the variation characteristics of the low and flood water levels at an identical discharge. Using the separation of variables method, we estimated the contributions of riverbed erosion, changes in downstream water levels, and riverbed roughness to water level variations.

\section{Materials and methods}

\subsection{Study area and data collection}

This study targeted the Yichang-Luoshan reach downstream of the Three Gorges Dam, a portion of the Yangtze River channel that extends for $408 \mathrm{~km}$, which can be divided into two parts: the Yichang-Zhicheng reach and the Jingjiang reach. Between Yichang and Luoshan, there are five hydrological stations, from which data was collected for this study, including Yichang, Zhicheng, Shashi, Jianli, and Luoshan (Figure 1). Discharged water flows into Dongting Lake through the Songzikou, Taipingkou, and Ouchikou outlets and then re-flows into the main stream of the Yangtze River near Qilishan.

Daily water discharge and water level data from the Yichang, Zhicheng, Shashi, Jianli, Luoshan, Songzikou, Taipingkou, Ouchikou, and Chenglingji stations from 1991-2016 were collected from the Bureau of Hydrology Changjiang Water Resources Commission (BHCWRC) (Table 1). Topographical data on the Yichang-Luoshan reach for 2002, 2009, and 2016 (October) were provided by the BHCWRC and the Yangtze River Waterway

Table 1 Hydrological and river topography data

\begin{tabular}{lllll}
\hline \multicolumn{1}{c}{ Hydrological station/Reach } & Data type & Data characteristics & Period & Data source \\
\hline $\begin{array}{l}\text { Yichang, Zhicheng, Shashi, } \\
\text { Jianli, and Luoshan }\end{array}$ & $\begin{array}{l}\text { Flow and } \\
\text { water level }\end{array}$ & $\begin{array}{l}\text { Daily, monthly, and } \\
\text { annual averages }\end{array}$ & 1991-2016 & $\begin{array}{l}\text { Yangtze River Waterway } \\
\text { Bureau and Bureau of }\end{array}$ \\
$\begin{array}{l}\text { Dongting Lake (three mouths) } \\
\text { Yichang-Chenglingji reach }\end{array}$ & Terrain & Sediment amount & $\begin{array}{l}\text { Hydrology Changjiang } \\
\text { 2002-2016 }\end{array}$ & $\begin{array}{l}\text { Water Resources Com- } \\
\text { mission }\end{array}$ \\
Yichang-Luoshan reach & Terrain & $1: 10,000$ & $\begin{array}{l}\text { October 2002, October } \\
\text { 2009, and October 2016 }\end{array}$ \\
\hline
\end{tabular}




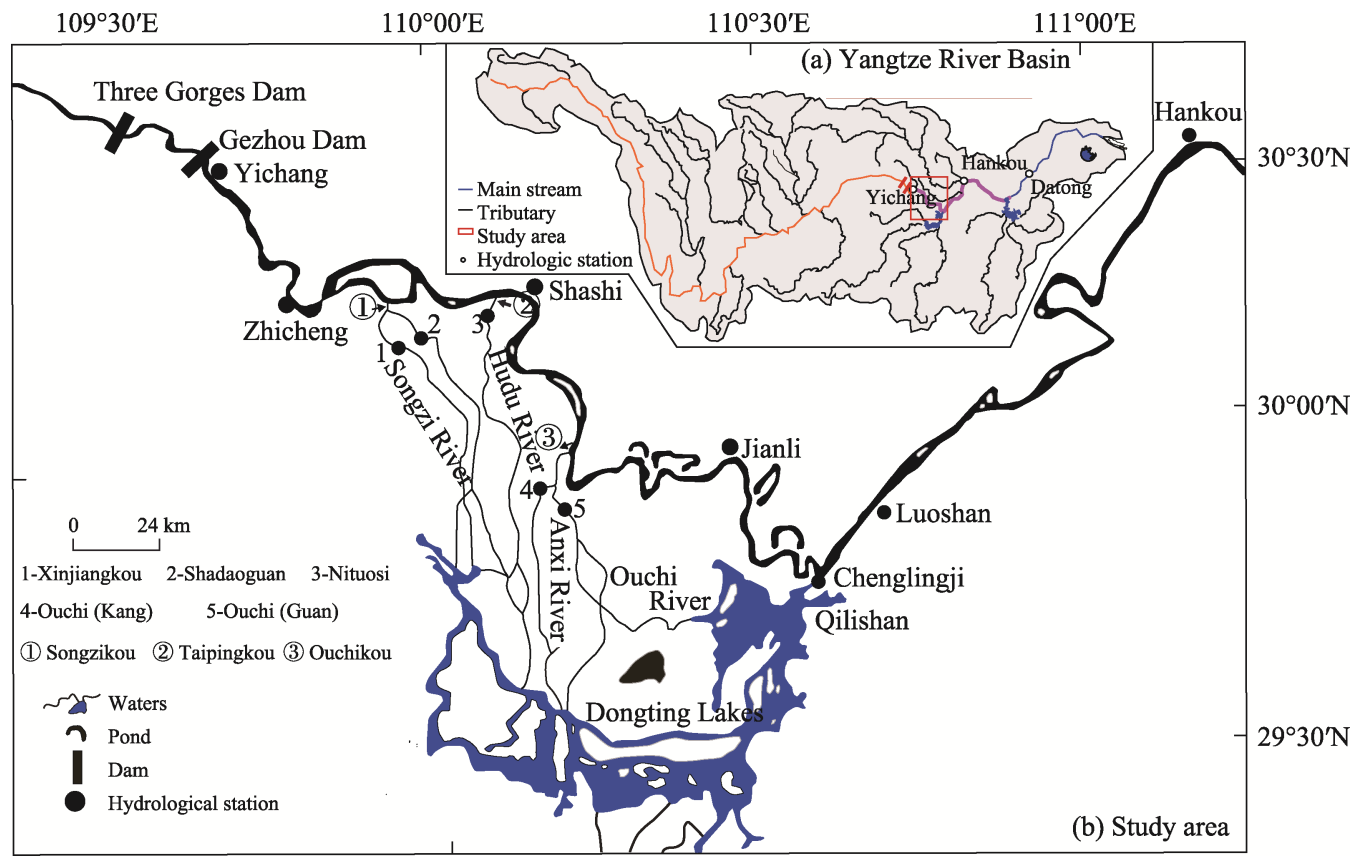

Figure 1 The location of the middle reaches (Yichang-Luoshan and Jingjiang reaches) of the Yangtze River

Administration. To analyze the effects that various riverbed factors have on the relationship between water discharge and water level during different operation periods of the Three Gorges Dam, we divided the study period into 1991-2003, 2003-2009, and 2009-2016.

\subsection{Methods}

The major influencing factors on water-level changes at a given discharge include riverbed erosion, riverbed roughness, and downstream control water level. The contribution of each factor can be estimated using the separation of variables method.

\subsubsection{Separation of variables method}

The separation of variables method is primarily based on river dynamic mechanics, which has been widely used to investigate the effects that individual factors have on variations in a river's water level (Guo et al., 2017; Li 2002; Dai et al., 2012; Cheng et al., 2012). The basic principles of this method are as follows.

Based on the flow equation (Eq. (1)), Chezy formula (Eq. (2)), and Manning formula (Eq. (3)), we can derive Eq. (4) as follows:

$$
\begin{gathered}
Q=A \cdot V \\
V=C \cdot R^{0.5} \cdot J^{0.5} \\
C=\frac{1}{n} \cdot R^{\frac{1}{6}} \\
Q=A \cdot \frac{1}{n} \cdot R^{\frac{2}{3}} \cdot J^{\frac{1}{2}}
\end{gathered}
$$




$$
J=\frac{Z_{\text {in }}-Z_{\text {out }}}{L}
$$

where $Q$ is the water discharge $\left(\mathrm{m}^{3} / \mathrm{s}\right), A$ is the discharge section area $\left(\mathrm{m}^{2}\right), V$ is the cross-sectional mean velocity $(\mathrm{m} / \mathrm{s}), C$ is the Chezy coefficient, $R$ is the hydraulic radius, $J$ is the water surface slope (\%o), $n$ is the riverbed roughness, $Z_{\text {in }}$ is the water level at the inlet section (m), $Z_{\text {out }}$ is the water level at the outlet section (m), and $L$ is the length of the river reach $(\mathrm{km})$.

Based on the assumption that the water discharge at the inlet section remains unchanged during the entire period, i.e., $Q=Q_{0}=Q_{1}$, we can derive Eq. (6) using Eqs. (4) and (5) as follows:

$$
Z_{\text {in } 1}-Z_{\text {in } 0}=\left(Z_{\text {out } 1}-Z_{\text {out } 0}\right)+\left[\left(\frac{A_{0}}{A_{1}}\right)^{2} *\left(\frac{n_{1}}{n_{0}}\right)^{2} *\left(\frac{R_{0}}{R_{1}}\right)^{4 / 3}-1\right] * J_{0} * L
$$

where subscripts 0 and 1 represent the beginning of the study period and its end, respectively, subscripts "in" and "out" represent the inlet and outlet sections, respectively, $Z_{\text {in } 1}-Z_{\text {in } 0}$ is the change in the water level at the inlet section, $Z_{\text {out } 1}-Z_{\text {out } 0}$ is the change in the water level at the outlet section, $\left(A_{0} / A_{1}\right)^{2}$ represents the changes in the cross-sectional areas, $\left(\mathrm{n}_{1} / \mathrm{n}_{0}\right)^{2}$ represents the changes in riverbed resistance, and $\left(R_{0} / R_{1}\right)^{4 / 3}$ represents the changes in riverbed erosion.

\subsubsection{MIKE 11 HD model}

Based on separation of variables method, the MIKE 11 HD model was used to estimate the effects that riverbed erosion, riverbed roughness, and the downstream water level control have on the changes in the water level at a specific discharge. This model relies on the following Eqs. (7) and (8), where the water flow continuity and water dynamic equations are as follows:

$$
\begin{gathered}
\frac{\partial Q}{\partial x}+\frac{\partial A}{\partial t}=0 \\
\frac{\partial Q}{\partial t}+\frac{\partial}{\partial x}\left(\frac{Q^{2}}{A}\right)+g A \frac{\partial Z}{\partial x}+g \frac{n^{2} Q|Q|}{A R^{4 / 3}}=0
\end{gathered}
$$

where $Q$ is the water discharge $\left(\mathrm{m}^{3} / \mathrm{s}\right), A$ is the discharge section area $\left(\mathrm{m}^{2}\right), x$ is the range coordinate, $t$ is the time coordinate $(\mathrm{s}), g$ is the acceleration due to gravity $\left(\mathrm{m} / \mathrm{s}^{2}\right), Z$ is the water level (m), $n$ is the riverbed roughness, and $R$ is the hydraulic radius (m).

Topographical data for the Yichang-Luoshan reach from 2002, 2009, and 2016 were used as input to run the MIKE 11 HD model. The upper boundary condition was set as the daily water discharge at Yichang station while the daily water level at Luoshan station was used as the lower boundary condition. The water discharge at the three outlets (i.e., the Songzikou, Taipingkou, and Ouchikou outlets) and Chenglingji station were all based on daily data. By verifying the observed water level at the main hydrological stations throughout the Yichang-Luoshan reach, we were able to simulate the comprehensive riverbed roughness along the Yichang-Zhicheng, Zhicheng-Shashi, Shashi-Jianli, and Jianli-Luoshan reaches. As shown in Figure 2, the simulated water level essentially agrees with the observed values $(R>0.98)$, demonstrating acceptable model accuracy. 

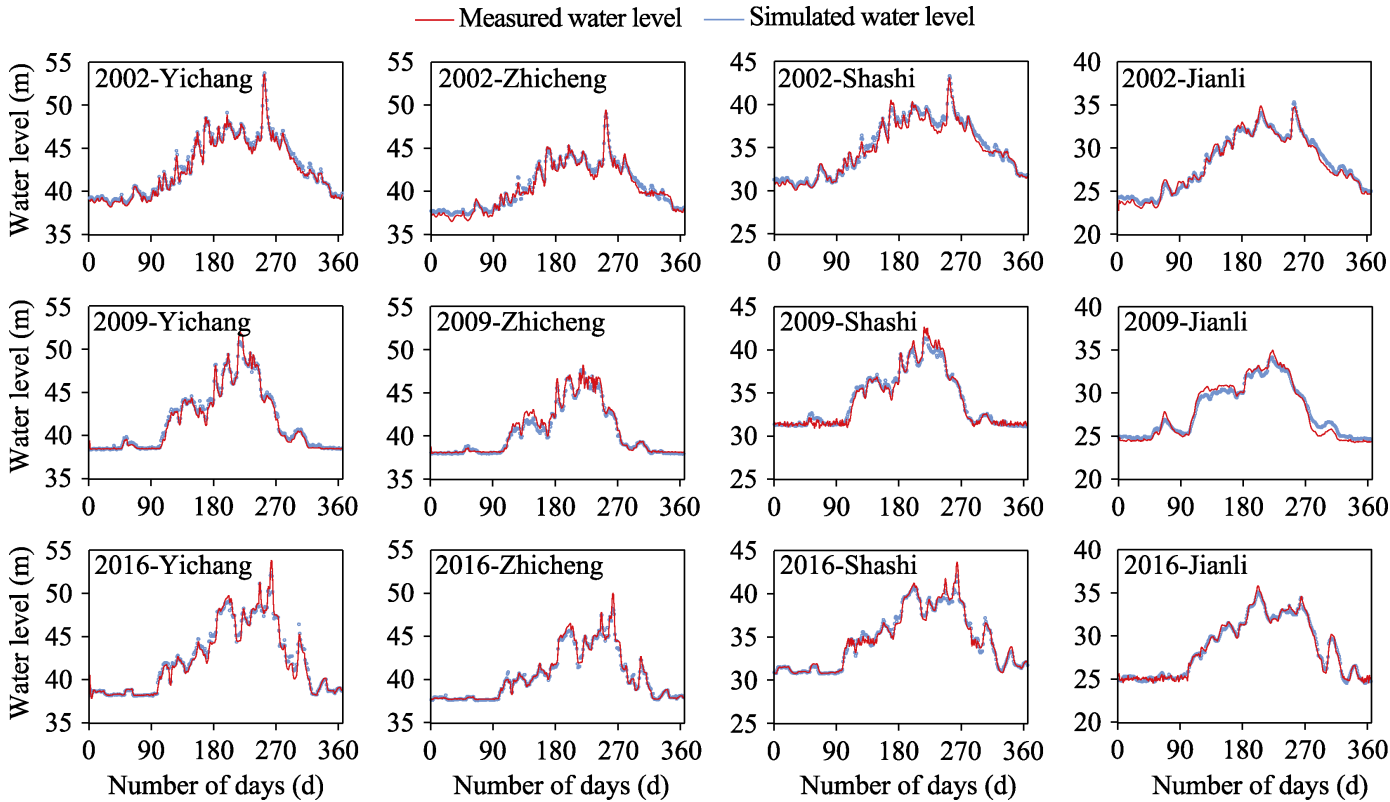

Figure 2 Measured and simulated water levels at the hydrological stations in 2002, 2009, and 2016

\subsubsection{Selection of representative water discharge rates}

The variation trends at the low and flood water levels are different for different reaches of the Yangtze River. Thus, a representative water discharge rate must be selected for each hydrological station (Yang et al., 2017a, 2017b, 2018; Han et al., 2017). Based on the daily water discharge data from 1991-2016 and the PIII curve, we selected water discharge rates with assurance rates of up to $90 \%$ and $10 \%$ as the low and flood water discharge values (Table 2), respectively, to investigate the water level variation characteristics.

Table 2 Representative discharge rates at the hydrological stations located along the middle reaches of the Yangtze River

\begin{tabular}{cccccc}
\hline Flow & Yichang & Zhicheng & Shashi & Jianli & Luoshan \\
\hline Low water flow $\left(\mathrm{m}^{3} / \mathrm{s}\right)$ & 6,190 & 6,490 & 6,460 & 6,490 & 8,460 \\
Flood flow $\left(\mathrm{m}^{3} / \mathrm{s}\right)$ & 46,500 & 46,400 & 37,600 & 34,500 & 45,800 \\
\hline
\end{tabular}

\section{Results}

\subsection{Water level-discharge rate relationship}

We selected 2003, 2010, and 2016 as representative years (Figure 3), observing that the low water level at a given discharge rate has a downward trend while the flood water level shows an increasing trend. This suggests the existence of a critical water discharge rate. If the water discharge was higher than this critical discharge rate, the water level had an increasing trend, and vice versa. Thus, the variation characteristics of the low and high water levels differed along the middle reaches of the Yangtze River. 

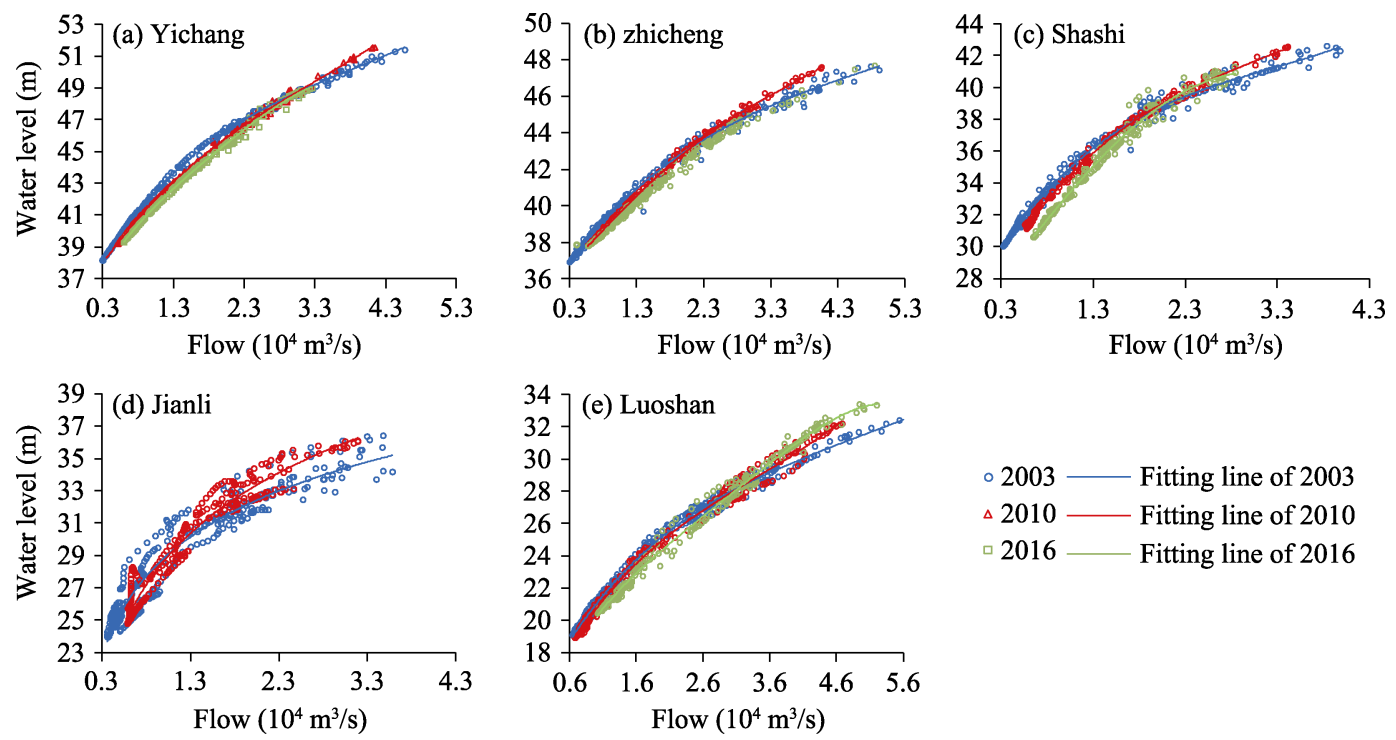

$$
\begin{aligned}
& \circ 2003-\text { Fitting line of } 2003 \\
& \triangle 2010-\text { Fitting line of } 2010 \\
& \square 2016-\text { Fitting line of } 2016
\end{aligned}
$$

Figure 3 Relationships between the water level and water discharge along the middle reaches of the Yangtze River in 2003, 2010, and 2016 at the five hydrological stations

\subsection{Changes in riverbed erosion}

During the period from October 2002 to November 2016 (Figure 4), the erosion volumes in the low-flow, basic, reach-scale bankfull, and flood-flow channels reached $9.90 \times 10^{8}$ $\mathrm{m}^{3}, 10.37 \times 10^{8} \mathrm{~m}^{3}, 11.01 \times 10^{8} \mathrm{~m}^{3}$, and $11.49 \times 10^{8} \mathrm{~m}^{3}$, respectively. Among them, the contributions of the low-flow and reach-scale bankfull channel erosion volumes to the total erosion volume reached $86.16 \%$ and $95.82 \%$, respectively, while the value for the high beach was $4.18 \%$. From October 2002 to October 2009, the riverbed scouring intensity enhanced in the low-flow channel. In contrast, the intensity decreased in the area between the low-flow and basic channels, basic and reach-scale bankfull channels, and reach-scale bankfull and flood-flow channels, indicating that riverbed erosion mainly occurs in the low-flow channel.

After operation of the Three Gorges Dam, there was a significant decrease in the number of cumulative days characterized by flood discharge rates. There were reductions in both the width of the flood channel and the frequency at which flooding occurred (Yang et al., 2017). Revetments, ports, wharves, and other water conservancy projects reduced the width of the flood channel, which may have negatively affected the flood water level and width of the flood channel (Zhang et al., 2011). From 2003-2016, most cross-sections of the low-flow, reach-scale bankfull, and flood-flow

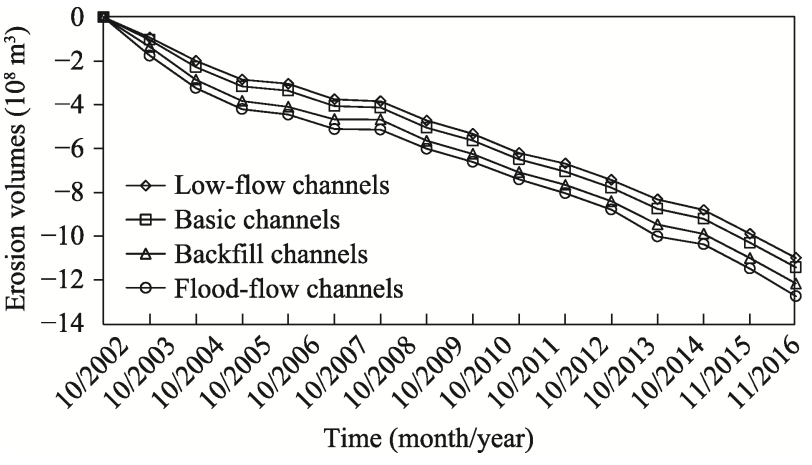

Figure 4 Cumulative riverbed erosion volumes along the middle reaches of the Yangtze River 
channels exhibited a widening trend, representing up to $71.7 \%, 60.1 \%$, and $55.5 \%$ of the total (173) cross-sections, respectively (Table 3). From 2009-2016, the number of low-flow cross-sections that experienced widening increased by $1.7 \%$, as compared with those from 2003-2009. In contrast, the number of flood-flow cross-sections that experienced widening decreased by $35.9 \%$. The cross-sections that had increases in their widths of greater than 20 and $50 \mathrm{~m}$ experienced widening at similar rates. Since 2009, the percentage of low-flow cross-sections that have experienced widening has further increased, mainly due to enhanced riverbed erosion. In contrast, the number of days with overbank floods, revetments, ports, wharves, and other human activity have primarily affected the lower percentage of flood-flow cross-sections with increased widths (Yang et al., 2017, 2018).

Table 3 Percentage of widened cross-sections along the Yichang-Chenglingji reach

\begin{tabular}{clccc}
\hline Time & Channel characteristics & $\Delta B>0 \mathrm{~m}$ & $\Delta B>20 \mathrm{~m}$ & \multicolumn{2}{c}{$\Delta B>50 \mathrm{~m}$} \\
\hline \multirow{2}{*}{$2003-2009$} & Low-flow channel & 68.8 & 41.6 & 28.9 \\
& Backfill channel & 71.7 & 27.2 & 16.2 \\
& Flood channel & 74.6 & 22.0 & 6.4 \\
\multirow{2}{*}{$2009-2016$} & Low-flow channel & 70.5 & 46.8 & 17.8 \\
& Backfill channel & 57.8 & 25.4 & 6.94 \\
& Flood channel & 38.7 & 14.5 & 43.9 \\
& Low-flow channel & 71.7 & 57.8 & 23.1 \\
\hline
\end{tabular}

Note: $\Delta B$ is the increased width of the cross-sections. The values in the third column are the percentages of increased widths higher than a value on the total number of cross-sections.

\subsection{Changes in riverbed roughness}

Since 2003, the sediment concentration along the middle reaches of the Yangtze River has been relatively low, which has caused riverbed scouring and coarsening (Yang et al., 2016; Zhang et al., 2017). The median sand particle size in the Yichang-Zhicheng riverbed has increased 59.6-fold, with the average values increasing from $0.63 \mathrm{~mm}$ in 2001 to $37.54 \mathrm{~mm}$ in 2009. The rate of particle-size increases along the Yichang-Yidu and Yidu-Zhicheng reaches are $97.6 \%$ and $108.3 \%$, respectively (Figure 5a). In 2015, the riverbed roughness along the Zhijiang, Shashi, Gongan, Shishou, and Jianli reaches increased by $2.7 \%, 2.4 \%$, $4.7 \%, 5.3 \%$, and $3.9 \%$, respectively (Figure $5 \mathrm{~b}$ ).
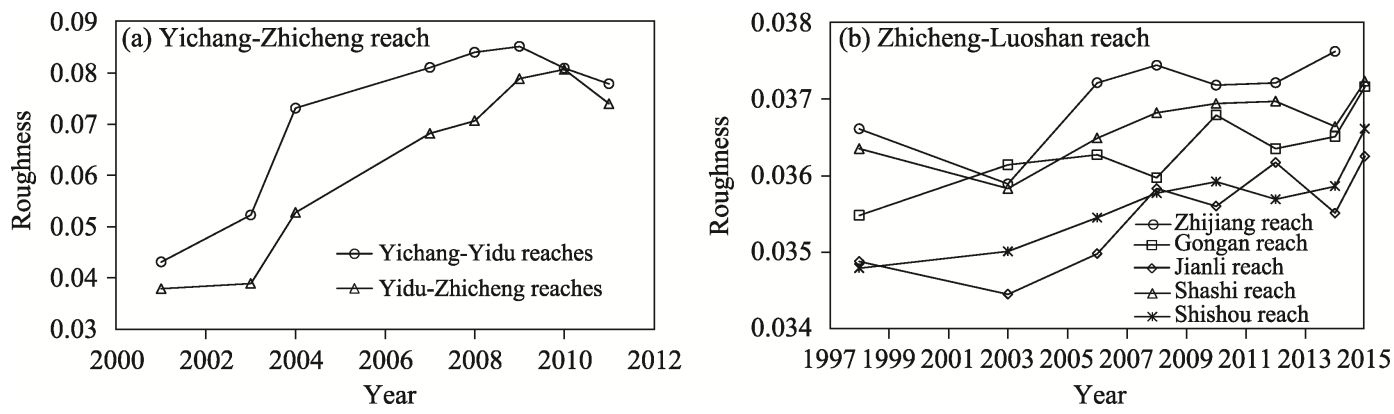

Figure 5 Estimation of the riverbed roughness along the middle reaches of the Yangtze River 


\section{Discussion}

The factors that influence changes in the water level at a specific discharge rate mainly include the riverbed geomorphology, riverbed roughness, and downstream water level control. To further estimate the contribution of each factor, we calculated the riverbed roughness along the Yichang-Zhicheng, Zhicheng-Shashi, Shashi-Jianli, and Jianli-Luoshan reaches using the MIKE $11 \mathrm{HD}$ model, with observed data on the riverbed geomorphology, daily water discharge, and daily water level from 2002, 2009, and 2016 as the input. Based on the control variable principle, we used input data concerning the riverbed geomorphology, riverbed roughness, and downstream water level control to the MIKE $11 \mathrm{HD}$ model to estimate the contributions of these factors to the changes in the water level at a specific discharge rate.

\subsection{Changes in low-flow water level and influencing factors}

\subsubsection{Changes in low-flow water level}

Using the least squares method, we determined the relationships between the daily water levels and daily discharge rates. Except for those at Yichang station in 2016 and Jianli station in 2015 , the correlation coefficients at the other hydrological stations were all higher than 0.95 . Based on the regression equation, we were able to calculate the water levels corresponding to their representative water discharge rates. From 1991-2003, the low-flow water level at each station showed a weak decreasing trend (Figure 6). In contrast, decreasing trends at Yichang, Zhicheng, Shashi, Jianli, and Luoshan stations became significantly enhanced after the operation of the Three Gorges Dam, with low-flow water levels decreasing by up to $4.98 \mathrm{~cm} / \mathrm{yr}, 6.26 \mathrm{~cm} / \mathrm{yr}, 13.51 \mathrm{~cm} / \mathrm{s}, 8.04 \mathrm{~cm} / \mathrm{yr}$, and $5.46 \mathrm{~cm} / \mathrm{yr}$ from 2003-2016. From 2003-2009, the low-flow water levels at Yichang, Zhicheng, Shashi, Jianli, and Luoshan stations reduced by $4.79 \mathrm{~cm} / \mathrm{yr}, 3.98 \mathrm{~cm} / \mathrm{yr}, 8.17 \mathrm{~cm} / \mathrm{yr}, 12.30 \mathrm{~cm} / \mathrm{yr}$, and $3.61 \mathrm{~cm} / \mathrm{yr}$, respectively. From 2009-2016, the water levels at these stations reduced by $3.48 \mathrm{~cm} / \mathrm{yr}, 7.23 \mathrm{~cm} / \mathrm{yr}$, $17.18 \mathrm{~cm} / \mathrm{yr}, 7.63 \mathrm{~cm} / \mathrm{yr}$, and $8.32 \mathrm{~cm} / \mathrm{yr}$. Thus, the low-flow water levels at Yichang and Jianli stations had a decreasing trend, as compared with the periods from 2009-2016 and 2003-2009, while those at Zhicheng, Shashi, and Luoshan stations had an increasing trend.
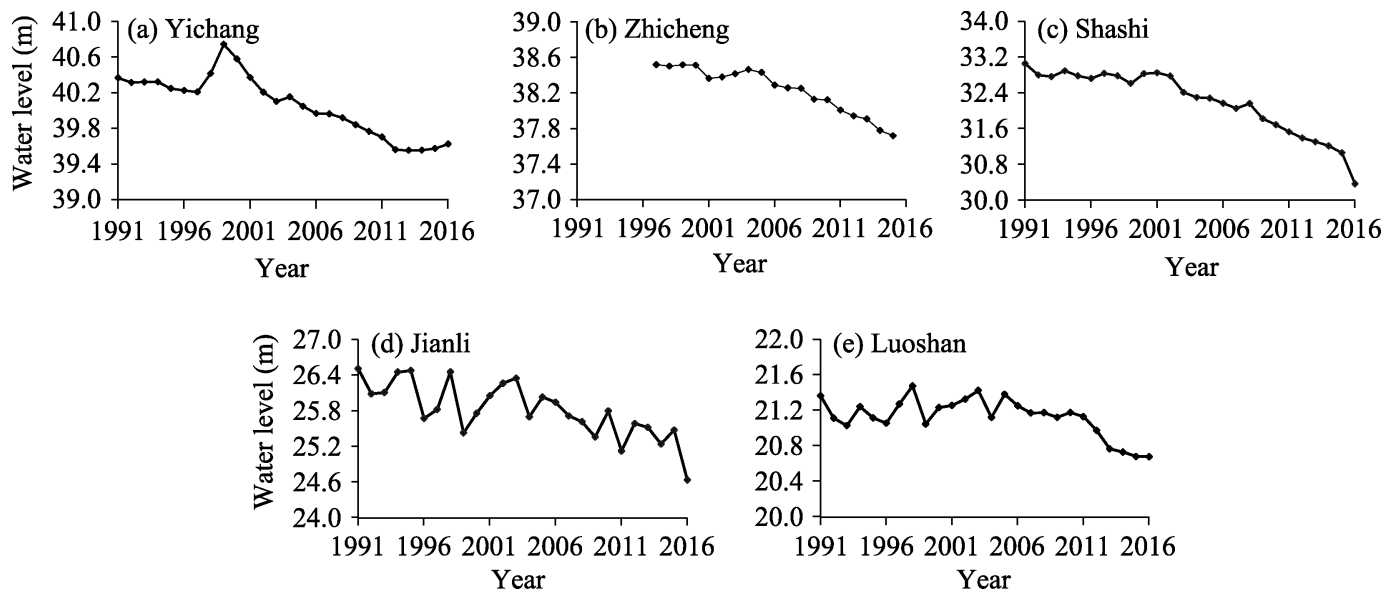

Figure 6 Variation trends in the average water level under the characteristic flows along the middle reaches of the Yangtze River 


\subsubsection{Influencing factors on changes in the low-flow water level}

Before the operation of the Three Gorges Dam in 2003, the low-flow water level showed a decreasing trend, which was mainly caused by riverbed erosion and cut-bend projects (Han et al., 2017). With the beginning of dam operation, riverbed erosion occurred widely in the reach-scale bankfull channel below the dam over long distances. Above the reach-scale bankfull channel, vegetation growth increased the riverbed resistance (Yang et al., 2017a, 2017b, 2018; Han et al., 2017). Similarly, ports, wharves, and channel works can also change the local riverbed resistance (Yang et al., 2016; Zhang et al., 2017), leading to changes in riverbed roughness. The downstream water level control had a significant effect on the upstream water level, especially during the flood-flow period. An increased downstream water level control can increase the upstream water level (Li et al., 2009), including the flood water level. Using the separation of variables method, we calculated the contributions of single and combined factors to the changes in the low-flow water level at a specific discharge rate. The results are as follows (Figure 7).

(1) From 2003-2016, the low-flow water levels at Yichang, Zhicheng, Shashi, and Jianli stations decreased by $0.48 \mathrm{~m}, 0.66 \mathrm{~m}, 1.73 \mathrm{~m}$, and $0.79 \mathrm{~m}$, respectively. From 2003-2009, the low-flow water levels at the same stations decreased by $0.26,0.13,0.62$, and $0.65 \mathrm{~m}$, respectively. From 2009-2014, the water levels decreased by $0.22 \mathrm{~m}, 0.53 \mathrm{~m}, 1.11 \mathrm{~m}$, and $0.14 \mathrm{~m}$, respectively.

(2) From 2003-2016, changes in the topography, riverbed roughness, and downstream water level control caused a reduction in the low-flow water level at Yichang, Zhicheng, Shashi, and Jianli stations, with reductions of up to $0.46 \mathrm{~m}, 0.74 \mathrm{~m}, 1.81 \mathrm{~m}$, and $0.82 \mathrm{~m}$, respectively. Among these influencing factors, reduced water levels attributable to changes in the river topography reached $0.47 \mathrm{~m}, 1.43 \mathrm{~m}, 2.38 \mathrm{~m}$, and $1.25 \mathrm{~m}$, respectively. The variations in the downstream water level also decreased the low-flow water levels, with effects reaching $0.32 \mathrm{~m}, 0.22 \mathrm{~m}, 0.11 \mathrm{~m}$, and $0.14 \mathrm{~m}$, respectively. In contrast, the increased riverbed roughness elevated the low-flow water levels, reaching $0.33 \mathrm{~m}, 0.91 \mathrm{~m}$, $0.68 \mathrm{~m}$, and $0.57 \mathrm{~m}$, respectively.

(3) Compared with the situation from 2003-2009, riverbed erosion from 2009-2016 decreased along the Yichang-Zhicheng reach, such that the effects of riverbed erosion on the low-flow water level also declined at Yichang station. Along the Zhicheng-Shashi and Shashi-Jianli reaches, the effects of riverbed erosion became more intense on the low-flow water level. This indicates that regions with severe riverbed erosion had migrated downstream to sandy riverbeds. At the same time, there was also an increase in the reduction of the upstream water level due to downstream riverbed erosion. At Jianli station, downstream riverbed erosion had little effect on the low-flow water level.

(4) Compared with 2003-2009, riverbed armoring along the Yichang-Zhicheng reach from 2009-2016 was basically completed. Thus, the influence of changes in riverbed roughness along this reach was alleviated. From 2009-2016, riverbed armoring along the Zhicheng-Shashi reach intensified. Thus, there was also an enhancement of the effects that the increased riverbed roughness along this reach had on the low-flow water levels. Along the Shashi-Jianli and Jianli-Luoshan reaches, the level of riverbed armoring was limited, thus having little effect on the low-flow water levels at Shashi and Jianli stations. 

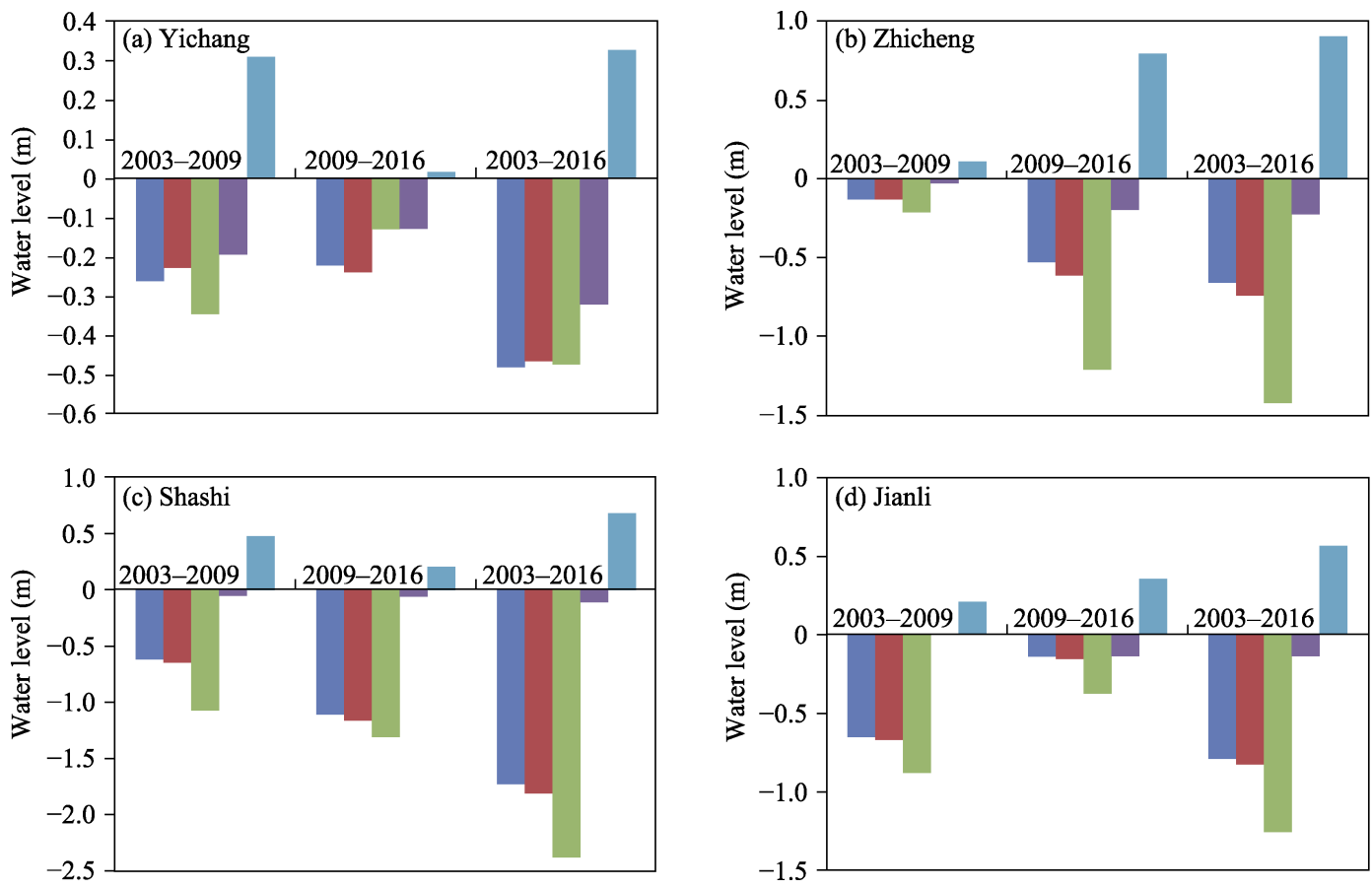

- Observed varied water level

Effect that all the influencing factors have on the low-flow water level

Effect that varied topography has on the low-flow water level

Effect that the changes in the downstream water level control have on the low-flow water level

Effect that changes in riverbed roughness have on the low-flow water level

Figure 7 Effects of the influencing factors on changes in the low water levels

In conclusion, from 2003-2016, riverbed erosion was the dominant factor that reduced the low-flow water level along the Yichang-Chenglingji reach. Since 2009, riverbed scouring along the Yichang-Zhicheng reach has weakened, such that there has also been a decrease in its contribution to the reduction of the low-flow water level. Along the Jingjiang reach, there has been a decrease in the contribution of riverbed erosion. Increased riverbed roughness restrained the reduced low-flow water level while this positive effect declined along the Yichang-Zhicheng reach since 2009 , as riverbed armoring was essentially completed. In contrast, the positive effects of riverbed armoring became more intense along the Jingjiang reach.

\subsection{Changes in flood water levels and influencing factors}

\subsubsection{Changes in flood water levels}

From 1991-2002, the flood water levels at a specific discharge rate showed no significant variation trends at the Yichang-Luoshan stations (Figure 8). In contrast, the flood water level has increased since 2003. The high water levels at Yichang, Zhicheng, Shashi, Jianli, and Luoshan stations from 2009-2016 increased by $0.42 \mathrm{~m}, 0.75 \mathrm{~m}, 0.61 \mathrm{~m}, 1.14 \mathrm{~m}$, and $0.63 \mathrm{~m}$, respectively, as compared with the high water levels from 2003-2009. When comparing the periods from 1991-2003, 2003-2009, and 2009-2016, we found that the flood-flow water level had variation trends characteristic of a "concave curve." Specifically, the flood water level first decreased and then increased (Table 4). Thus, variation characteristics for the 
istics for the flood-flow water level changed from "high discharge with a high water level" to "middle discharge with a high water level," which creates challenges for flood managers seeking to reduce pressure on flood defenses.
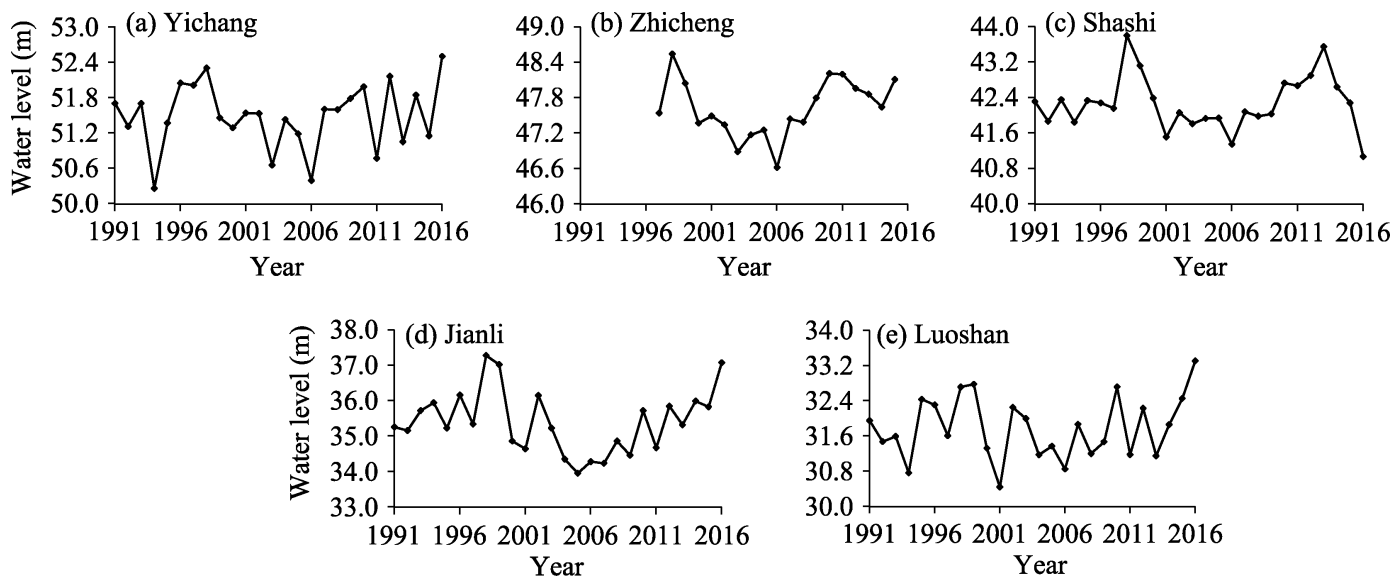

Figure 8 Variation trends in the flood water level exposed to characteristic flows along the middle reaches of the Yangtze River

Table 4 Variation characteristics for the flood water level (m)

\begin{tabular}{lccc}
\hline \multirow{2}{*}{ Hydrological station } & \multicolumn{3}{c}{ Period of time } \\
\cline { 2 - 4 } & $1991-2003$ & $2003-2009$ & $2009-2016$ \\
\hline Yichang & 51.48 & 51.24 & 51.66 \\
Zhicheng & 47.60 & 47.22 & 47.97 \\
Shashi & 42.29 & 41.87 & 42.48 \\
Jianli & 35.69 & 34.48 & 35.61 \\
Luoshan & 31.87 & 31.47 & 32.05 \\
\hline
\end{tabular}

In general, larger-scale riverbed erosion is mainly distributed in the low-flow channel, which reduces the water level in rivers. The reduced water level was mainly due to a reduced low-flow water level. We suggest that, from 2003-2009 and 2009-2016, the Jingjiang reach experienced scouring while the flood water level exhibited no significant downward trend. Compared with that from 2003-2009, the number of days of overbank flooding decreased from 2009-2016 due to the operation of cascade reservoirs, which increased vegetation growth in the river system. The increased vegetation growth increased the riverbed resistance, thus increasing the flood water level. Simultaneously, numerous waterway regulation works, including revetments, bridges, and ports, were completed during 2009-2016, further increasing the flood water level.

\subsubsection{Influencing factors on flood water levels}

Before the operation of the Three Gorges Dam, the flood water level showed no evident variation trends at Yichang, Zhicheng, and Shashi stations. Along the Jianli-Luoshan reach, sedimentation of the riverbed was the dominant reason for the increased high water level ( $\mathrm{Li}$ et al., 2009), along with the reduced floodwater storage area (Zhang et al., 2016). Using the 
separation of variables method, we estimated the contributions of single and combined factors to the changes in the high water level. The results are as follows (Figure 9).

(1) From 2003-2016, the high water levels at a specific discharge rate increased by 0.41 $\mathrm{m}, 0.69 \mathrm{~m}, 0.71 \mathrm{~m}$, and $1.53 \mathrm{~m}$ at Yichang, Zhicheng, Shashi, and Jianli stations, respectively, from 2003-2009, the values were $0.36 \mathrm{~m}, 0.63 \mathrm{~m}, 0.10 \mathrm{~m}$, and $0.11 \mathrm{~m}$, respectively, and the values from $2009-2016$ were $0.05 \mathrm{~m}, 0.06 \mathrm{~m}, 0.61 \mathrm{~m}$, and $1.42 \mathrm{~m}$, respectively.

(2) From 2003-2016, the total effects that the changes in the riverbed topography, riverbed roughness, and downstream water level control had on the flood water level at Yichang, Zhicheng, Shashi, and Jianli stations were $0.41 \mathrm{~m}, 0.69 \mathrm{~m}, 0.76 \mathrm{~m}$, and $1.46 \mathrm{~m}$, respectively. The decrease in the flood water levels is attributable to riverbed erosion that reached $0.70 \mathrm{~m}$, $1.26 \mathrm{~m}, 0.74 \mathrm{~m}$, and $0.41 \mathrm{~m}$, respectively. Changes in the downstream water level control increased the flood water levels up to $0.39 \mathrm{~m}, 0.23 \mathrm{~m}, 0.33 \mathrm{~m}$, and $0.17 \mathrm{~m}$, respectively. The increased riverbed roughness also increased the flood water level by up to $0.72 \mathrm{~m}, 1.72 \mathrm{~m}$, $1.17 \mathrm{~m}$, and $1.70 \mathrm{~m}$, respectively.
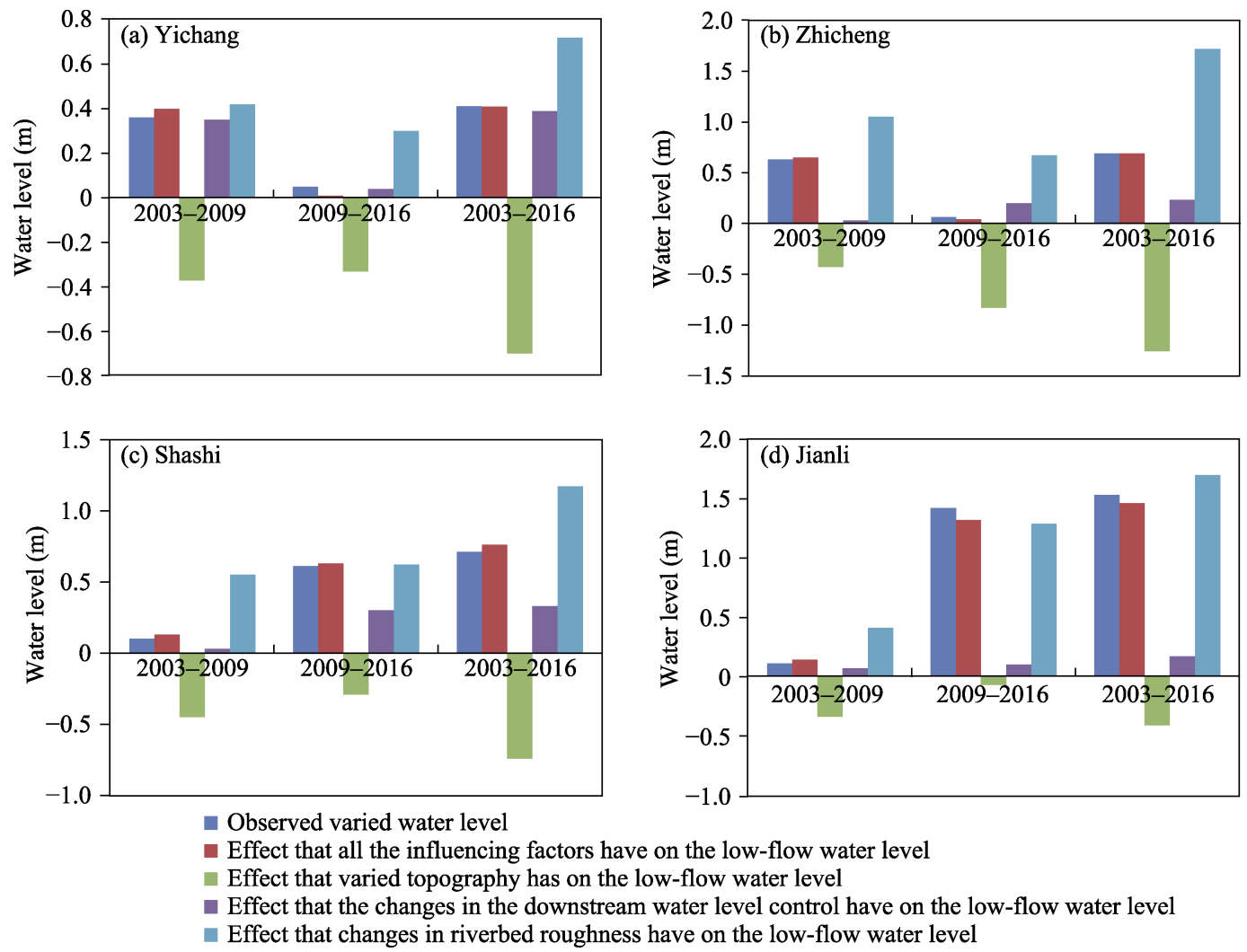

Figure 9 Effects of the influencing factors on the changes in the flood water level

(3) The effects of riverbed erosion on the reduced flood water level at Yichang, Shashi, and Jianli stations were mitigated from 2009-2016 compared with those from 2003-2009. In contrast, riverbed erosion along the Zhicheng-Shashi reach intensified, which further reduced the high water level. Greater riverbed armoring occurred from 2003-2009 than in 2009-2016. Thus, changes in the riverbed roughness had little effect on the flood water level 
along the Yichang-Zhicheng and Zhicheng-Shashi reaches from 2009-2016, with a relatively reduction of its contributions. From 2003-2009, variations in the downstream water level control had highly significant effects on the flood water level at Yichang station, whereas it had little effect on the high water level at Yichang, Shashi, and Jianli stations, contributing changes of less than $0.10 \mathrm{~m}$. From 2009-2016, the effects of the downstream water level control were minor at Yichang station, whereas changes at Zhicheng, Shashi, and Jianli stations were $0.10-0.30 \mathrm{~m}$.

In conclusion, the increased riverbed roughness was the dominant factor that increased the flood water level. Since 2009, riverbed armoring has been basically complete along the Yichang-Zhicheng reach, such that there was a reduction in its effects. Along the Jingiiang reach, the effects of riverbed armoring intensified. Riverbed erosion mitigated the increased high water level during the flood season while the contributions of these effects have decreased along the Yichang-Zhicheng reach since 2009. In contrast, the effects of riverbed erosion on the increased high water level in the Jingjiang reach intensified due to increased riverbed scouring.

\section{Conclusions}

This study investigated the Jingjiang reach in the middle reaches of the Yangtze River. Using the polynomial regression curve fitting method, we analyzed the variation characteristics of the water levels at representative water discharge rates. Using the MIKE 11 HD model and separation of variables method, we estimated the contributions of changes in the riverbed topography, riverbed roughness, and downstream water level control to water level variations from 1991-2003, 2003-2009, and 2009-2016. Our main conclusions are as follows.

(1) From 1991-2016, the low-flow water level showed a downward trend, which intensified after 2009. From 1991-2016, the flood-flow water level in Jingjiang first decreased and then increased. Before 2003, the high water level can be characterized as "high water discharge at high water levels," whereas after 2003, the high water level was better characterized as "medium water discharge at high water levels."

(2) Riverbed erosion was the dominant factor that affected the reduced low-flow water level along the Yichang-Chenglingji reach. Since 2009, riverbed scouring decreased along the Yichang-Zhicheng reach, such that the effects of riverbed erosion on the reduced low water levels also decreased. Along the Jingjiang reach, riverbed scouring intensified, which also increased the reductions to the low-flow water level. The increased riverbed roughness inhibited reductions in the low-flow water level. Since 2009, riverbed armoring has been basically completed along the Yichang-Zhicheng reach, such that it has had little effect on inhibiting reductions to the water level. However, riverbed armoring remained intense throughout the Jingiiang reach, further mitigating reductions to the low-flow water levels.

(3) Increased riverbed roughness was the dominant factor affecting the increased high water level. Since 2009, riverbed armoring throughout the Yichang-Zhicheng reach was basically completed, such that this factor had little effect on the increased high water level. In contrast, the effects of riverbed armoring increased along the Jingjiang reach while riverbed erosion mitigation increases in the high water level. Since 2009, the riverbed along the Yichang-Zhicheng reach experienced reduced scouring, such that there was a reduction in 
the restraining effect of scouring on high water level increases. In contrast, the effects that riverbed erosion had on constraining the increased high water level intensified.

In this study, we did not consider the effects of riverbed erosion in the three outlets, river flow diversion, or embouchement on erosion in the main stream riverbed nor on the relationship between the water discharge rate and water level. Riverbed roughness was estimated using models affected by vegetation growth and navigation projects. In future studies, we will consider the above effects as potential factors that influence the relationship between the water levels and discharge rates.

\section{References}

Bormann H, Pinter N, Elfert S, 2011. Hydrological signatures of flood trends on German Rivers: Flood frequencies, flood heights and specific stages. Journal of Hydrology, 404(1/2): 50-66.

Burns A, Walker K F, 2015. Effects of water level regulation on algal biofilms in the River Murray, South Australia. River Research and Applications, 16(5): 433-444.

Carle M V, Sasser C E, Roberts H H, 2015. Accretion and vegetation community change in the Wax Lake delta following the historic 2011 Mississippi River flood. Journal Coastal Research, 313(3): 569-587.

Chai Y F, Li Y T, Yang Y P et al., 2019. Water level variation characteristics under the impacts of extreme drought and the operation of the Three Gorges Dam. Frontiers Earth Science, 13(3): 510-522.

Cheng J H, Xiang R, Qiu X F et al., 2012. Analysis of the impact on roughness of riverbed erosion downstream the Three Georges Project. Express Water Resources \& Hydropower Information, 33(7): 59-63. (in Chinese)

Dai S P, Yan J B, Zou T et al., 2012. A study of the impact of bottle-neck reach evolution downstream from Gezhouba on Yichang low water level. Express Water Resources \& Hydropower Information, 33(7): 40-44. (in Chinese)

Gabriel A, 2004. Impacts, perceptions, and management of shoreline hazards and water levels on a fluctuating reservoir: A case study of the Winnebago System, Wisconsin. Lake Reservoir Management, 20(3): 197-210.

Greene S L, Knox J C, 2014. Coupling legacy geomorphic surface facies to riparian vegetation: Assessing red cedar invasion along the Missouri River downstream of Gavins Point Dam, South Dakota. Geomorphology, 204(1): 277-286.

Guo Y, Sun Z H, Luo F B, 2017. Time-variation characteristics and causes of Yichang low-water level since impoundment of Three Gorges Reservoir. Hydro-Science and Engineering, (4): 35-42. (in Chinese)

Han J Q, Sun Z H, Li Y T et al., 2011. Changes and causes of lower water level in Yichang - Chenglingji reach after impounding of Three Gorges Reservoir. Engineering Journal of Wuhan University, 44(6): 685-690. (in Chinese)

Han J Q, Sun Z H, Li Y T et al., 2017. Combined effects of multiple large-scale hydraulic engineering on water stages in the middle Yangtze River. Geomorphology, 298: 31-40.

Han J Q, Sun Z H, Yang Y P, 2017. Flood and low stage adjustment in the middle Yangtze River after impoundment of the Three Gorges Reservoir (TGR). Journal of Lake Sciences, 29(5): 1217-1226. (in Chinese)

Huang X L, Wang W K, Zhu M H et al., 2016. "2016.7” flood last danger analysis and revelation in the middle and lower reaches of the Yangtze River. China Flood \& Drought Management, (5): 47-49. (in Chinese)

Lai X J, Jiang J H, Yang G S et al., 2014. Should the Three Gorges Dam be blamed for the extremely low water levels in the middle-lower Yangtze River? Hydrological Processes, 28(1): 150-160.

Li Y T, Sun Z H, Liu Y et al., 2009. Channel degradation downstream from the Three Gorges Project and its impacts on flood level. Journal of Hydraulic Engineering, 135(9): 718-728.

Li Y Z, 2002. Change in Yangtze water level along Yichang stretch in dry season. China Three Gorges Construction, 9(5): 12-14. (in Chinese)

Lu J Y, 1994. Variation of stage-discharge relationship of downstream of hydro-junction. Hydro-Science and En- 
gineering, (1/2): 109-117. (in Chinese)

Mei X F, Dai Z J, Du J Z et al., 2016. Linkage between Three Gorges Dam impacts and the dramatic recessions in China's largest freshwater lake, Poyang Lake. Scientific Reports, 5: 18197.

Moshe L B, Haviv I, Enzel Y et al., 2008. Incision of alluvial channels in response to a continuous base level fall: Field characterization, modeling, and validation along the Dead Sea. Geomorphology, 93(3/4): 524-536.

Shields J R, Douglas F, Simon A et al., 2000. Reservoir effects on downstream river channel migration. Environmental Conservation, 27(1): 54-66.

Sun Z H, Huang Y, Cao Q X et al., 2015. Spatial and temporal variations of the low flow stage in the immediate downstream reach of the Three Georges Dam. Journal of Basic Science and Engineering, 23(4): 694-704. (in Chinese)

Surian N, Ziliani L, Comiti F et al., 2010. Channel adjustments and alteration of sediment fluxes in gravel - bed rivers of North-Eastern Italy: Potentials and limitations for channel recovery. River Research \& Applications, 25(5): 551-567.

Topping D J, Schmidt J C, Vierra L E, 2013. Computation and analysis of the instantaneous discharge for the Colorado River at Lees Ferry, Arizona. USA: US Geological Survey Professional Paper, 30-33.

Yang Y P, Zhang M J, Li Y T et al., 2016. Suspended sediment recovery and bedsand compensation mechanism affected by the Three Gorges Project. Acta Geographica Sinica, 71(7): 1241-1254. (in Chinese)

Yang Y P, Zhang M J, Liu W L et al., 2019. Relationships between waterway depth and low-flow water levels in reaches below the Three Gorges Dam. Journal of Waterway, Port, Coastal, and Ocean Engineering, 145(1): 04018032.

Yang Y P, Zhang M J, Sun Z H et al., 2017a. The relationship between water level change and river channel geometry adjustment in the downstream of the Three Gorges Dam (TGD). Acta Geographica Sinica, 72(5): 776-789. (in Chinese)

Yang Y P, Zhang M J, Sun Z H et al., 2018. The relationship between water level change and river channel geometry adjustment in the downstream of the Three Gorges Dam. Journal of Geographical Sciences, 28(12): 1943-1961.

Yang Y P, Zhang M J, Zhu L L et al., 2017b. Influence of large reservoir operation on water-levels and flows in reaches below dam: Case study of the Three Gorges Reservoir. Scientific Reports, 7: 15640.

Yuan W H, Yin D W, Finlayson B et al., 2012. Assessing the potential for change in the middle Yangtze River channel following impoundment of the Three Gorges Dam. Geomorphology, (147/148): 27-34.

Zhang M, Zhou J J, Huang G X 2016. Flood control problems in middle reaches of Yangtze River and countermeasures. Water Resources Protection, 32(4): 1-10. (in Chinese)

Zhang W, Yang Y P, Zhang M J et al., 2017. Mechanisms of suspended sediment restoration and bed level compensation in downstream reaches of the Three Gorges Projects (TGP). Journal of Geographical Sciences, 27(4): 463-480.

Zhang X B, Lu J Y, Lin Q S, 2011. Preliminary study on accumulated influence of the bankline use on flood control in the middle and lower reaches of the Yangtze River. Resources and Environment in the Yangtze Basin, 20(9): 1138-1142. (in Chinese) 